\section{BMJ Open \\ Respiratory \\ Research}

\title{
Impact of surgical maxillomandibular advancement upon pharyngeal airway volume and the apnoea-hypopnoea index in the treatment of obstructive sleep apnoea: systematic review and meta-analysis
}

Maria Giralt-Hernando (D) , ${ }^{1}$ Adaia Valls-Ontañón, ${ }^{1,2}$ Raquel Guijarro-Martínez,, ${ }^{1,2}$ Jorge Masià-Gridilla, ${ }^{1,2}$ Federico Hernández-Alfaro ${ }^{1,2}$

To cite: Giralt-Hernando M, Valls-Ontañón A, GuijarroMartínez R, et al. Impact of surgical maxillomandibular advancement upon pharyngeal airway volume and the apnoea-hypopnoea index in the treatment of obstructive sleep apnoea: systematic review and meta-analysis. BMJ Open Resp Res 2019;6:e000402. doi:10.1136/ bmjresp-2019-000402

- Additional material is published online only. To view, please visit the journal online (http://dx.doi.org/10. 1136/bmjresp-2019-000402).

MG-H and AV-O contributed equally.

Received 5 January 2019 Revised 6 September 2019 Accepted 6 September 2019
Check for updates

(c) Author(s) (or their employer(s)) 2019. Re-use permitted under CC BY-NC. No commercial re-use. See rights and permissions. Published by BMJ.

For numbered affiliations see end of article.

Correspondence to Dr Maria Giralt-Hernando; mariagiralth@gmail.com

\section{ABSTRACT}

Background A systematic review was carried out on the effect of surgical maxillomandibular advancement (MMA) on pharyngeal airway (PA) dimensions and the apnoeahypopnoea index (AHI) in the treatment of obstructive sleep apnoea (OSA), with the aim of determining whether increased PA in the context of MMA is the main factor conditioning the subsequent decrease in $\mathrm{AHI}$.

Methods A search was made of the PubMed, Embase, Google Scholar and Cochrane databases. A total of 496 studies were identified. The inclusion criteria were a diagnosis of moderate to severe OSA, MMA success evaluated by polysomnography, reporting of the magnitude of MMA achieved, PA increase and a minimum follow-up of 6 months.

Results Following application of the eligibility criteria, eight articles were included. Metaregression analysis showed MMA to significantly increase both pharyngeal airway volume (PAV) (mean $7.35 \mathrm{~cm}^{3}$ (range 5.35-9.34)) and pharyngeal airway space (mean $4.75 \mathrm{~mm}$ (range 3.15 6.35)) and ensure a final AHI score below the threshold of 20 (mean 12.9 events/hour).

Conclusions Although subgroup analysis showed MMA to be effective in treating OSA, more randomised trials are needed to individualise the required magnitude and direction of surgical movements in each patient, and to standardise the measurements of linear and nonlinear PAV parameters.

\section{STUDY IMPACT}

Continuous positive airway pressure (CPAP) is acknowledged to be the gold standard treatment for obstructive sleep apnoea (OSA), though the adherence (defined as $>4$ hours of night use of CPAP for $70 \%$ of nights) failure rate reportedly reaches $46 \%-83 \%$ over the long term. Different surgical procedures have therefore been proposed, of which maxillomandibular advancement (MMA) has been shown to be the most effective option for treating OSA in selected patients, with an $86 \%$ success rate (defined as a final apnoea-hypopnoea index value of $<20$ events/hour and a reduction of $50 \%$ postoperatively). However, to our knowledge, no studies have examined the relationship between the impact of MMA surgery and the pharyngeal airway volume-related and polysomnography-related parameters of patients with moderate to severe OSA.

\section{INTRODUCTION}

Obstructive sleep apnea (OSA) is defined as a sleep-related breathing disorder characterised by respiratory pauses secondary to partial (hypopnoeic) or complete (apnoeic) obstruction of the pharyngeal airway (PA), with a duration of at least $10 \mathrm{~s} .{ }^{1}$ The PA is occluded due to a loss of muscle tone of the dilator muscles during sleep, which leads to its narrowing or total obstruction. ${ }^{12}$ As a result, there are repetitive oxygen desaturations $\left(\mathrm{SatO}_{2}\right)$ with snoring, unrefreshing sleep, fatigue and excessive daytime sleepiness (EDS). ${ }^{12}$ Systemic arterial hypertension and heart failure may subsequently develop, with a significant increased in mortality risk. ${ }^{12}$ Overall, OSA may also have a social impact in terms of poor quality of life, days of work lost and traffic accidents. ${ }^{2}$

It is estimated that OSA affects $5 \%-20 \%^{3}$ of the general adult population, though some authors report figures of up to $26 \% .{ }^{34}$ Nevertheless, the statistics show that over $50 \%$ of all cases go undiagnosed. ${ }^{3}$ The disorder is three times more common in men than in women. ${ }^{34}$ 
The diagnosis of OSA requires the recording of multiple physiological signals during sleep. ${ }^{4}$ In this regard, polysomnography (PSG) is considered the gold standard for diagnosing the disease. ${ }^{4}$ PSG records brain activity, breathing, heart rate, muscle activity, snoring, blood oxygen levels while resting/sleeping and repeated episodes of PA obstruction, which are measured by the apnoea-hypopnoea index (AHI) ${ }^{4}$ In addition, the guidelines of the American Academy of Sleep Medicine ${ }^{4}$ indicate that either PSG or home sleep apnoea testing can be used for the diagnosis of uncomplicated OSA in adults, although standard sleep channels are not monitored in the latest devices (eg, electroencephalogram). ${ }^{4}$

Different methods are currently used for treating patients with OSA. ${ }^{5}$ Continuous positive airway pressure (CPAP) is considered the gold standard in this regard. However, CPAP non-adherence rates of $46 \%-86 \%$ have been reported ${ }^{5}$ (adherence being defined as $>4$ hours of night use of CPAP during $70 \%$ of nights). ${ }^{6}$ Different alternative treatments are available to expand the PA, such as uvulopalatopharyngoplasty (UPPP), tonsillectomy, adenoidectomy, hyoid suspension (Hs) or hyothyroidopexy, ${ }^{5}$ though the cure rate (CR) (defined as a final AHI of $<5$ events/hour) does not exceed $40 \%$, and the results do not hold up over time. ${ }^{78}$

Since Guilleminault $e t a l^{7}$ first described maxillomandibular advancement (MMA) as an effective treatment for patients with OSA with a retrusive facial profile in 1976, several studies have confirmed its benefits. ${ }^{78}$ Many publications have demonstrated that MMA moves the anterior pharyngeal wall forwards, resulting in enlargement of the PA and, consequently, a decrease in AHI. ${ }^{1}{ }^{3}$ 8-11 Some authors have concluded that the efficacy of MMA is equivalent to that of CPAP use over the long term. ${ }^{5710}$ Accordingly, MMA with or without adjunctive surgical procedures is the most effective and predictable surgical treatment option for patients diagnosed with moderate to severe OSA, with a $50 \%$ and $86 \%$ CR and surgical success rate (SR), respectively (SR, defined as final AHI of $<20$ events/hour, and its reduction by $50 \%) .{ }^{8}$ Thus far, a mean MMA of 10-12 $\mathrm{mm}$ has been described as the standard advancement required to treat adult patients with moderate to severe OSA. ${ }^{71-13}$ Mean linear maxillary and mandibular advancements of $8.07 \pm 2.60 \mathrm{~mm}$ and $10.8 \pm 2.34 \mathrm{~mm}$, respectively, have been reported in the literature. ${ }^{13}$ However, the magnitude of MMA required at the time of surgery in order to cure OSA depends on the patient's dentofacial characteristics (eg, retrognathia, maxillary hypoplasia and micrognathia), among other factors. ${ }^{581112}$

Recent studies have evaluated PA enlargement after MMA, reporting significant changes in pharyngeal airway volume (PAV) (a mean $80.43 \%$ vol gain), related to a mean decrease in AHI of $83.01 \%(\mathrm{p}<0.001) .{ }^{13}$ These volumetric parameters are usually quantified using cone beam CT (CBCT), ${ }^{258-101415}$ since the use of three-dimensional (3D) computer-aided planning technology with CBCT, compared with conventional planning with two-dimensional (2D) cephalometry, has been proven to be more accurate at treatment planning and follow-up and thus more beneficial for the patient. ${ }^{16}$ Nowadays, there is an emerging interest in the 3D study of the impact of orthognathic surgery on PAV, evaluating the impact of each single maxillomandibular movement on the three dimensions and at each level of the PA in the context of OSA approach. ${ }^{16}$

The aim of the present systematic review and meta-analysis was to assess the impact of MMA on PAV and AHI in the treatment of OSA.

\section{MATERIALS AND METHODS}

\section{Search strategy}

A systematic search was conducted of the PubMed, Embase, Cochrane Library and Google Scholar Beta databases on the upper airway and polysomnographic changes following MMA for OSA treatment. The study was based on the following PICO question (population: patients with OSA, intervention: MMA, comparison: magnitude of MMA, outcome: final PA dimensions and final AHI): how does MMA surgery affect PAV and, consequently, AHI in patients with OSA?

The PubMed search was conducted with the following Medical Subject Headings (MeSH) entry terms and thesaurus vocabulary for indexing articles: (("Orthognathic surgery" OR "Orthognathic Surgeries" OR "Surgeries, Orthognathic" OR "Surgery, Orthognathic" OR "Maxillofacial Orthognathic Surgery" OR "Maxillofacial Orthognathic Surgeries" OR "Orthognathic Surgeries, Maxillofacial" OR "Orthognathic Surgery, Maxillofacial" OR "Surgeries, Maxillofacial Orthognathic" OR "Surgery, Maxillofacial Orthognathic" OR "Jaw Surgery" OR "Jaw Surgeries" OR "Surgeries, Jaw" OR "Surgery, Jaw" OR "Orthognathic Surgical Procedures" OR "mandibular setback" OR " mandibular advancement" OR "maxillary setback" OR "maxillary advancement" OR "bimaxillary surgery" OR" maxillomandibular advancement”) AND ("Polysomnographies" OR "Monitoring, Sleep" OR "Sleep Monitoring" OR "Somnography" OR "Somnographies" OR "oximetry" OR "Oximetry" OR "Oximetries" OR "Oximetry, Pulse" OR "Oximetries, Pulse" OR "Pulse Oximetries" OR "Pulse Oximetry") AND ("Sleep Disordered Breathing" OR "Apneas, Obstructive Sleep" OR "Obstructive Sleep Apneas" OR "Sleep Apneas, Obstructive" OR "Obstructive Sleep Apnea Syndrome" OR "Obstructive Sleep Apnea" OR "OSAHS" OR "Syndrome, Sleep Apnea, Obstructive" OR "Apnea, Obstructive Sleep" OR "Sleep Apnea Hypopnea Syndrome" OR "Syndrome, Obstructive Sleep Apnea" OR "Upper Airway Resistance Sleep Apnea Syndrome" OR "Syndrome, Upper Airway Resistance, Sleep Apnea" or "Apnea Syndrome, Sleep" OR "Apnea Syndromes, Sleep" OR "Sleep Apnea Syndrome" OR "Apnea, Sleep" OR "Apneas, Sleep" OR "Sleep Apnea" OR "Sleep Apneas" OR "Sleep Hypopnea" OR "Hypopnea, Sleep" OR "Hypopneas, Sleep" OR "Sleep Hypopneas" OR "Sleep-Disordered Breathing" 
OR "Breathing, Sleep-Disordered" OR "Sleep Disordered Breathing" OR "Sleep Apnea, Mixed Central and Obstructive" OR "Mixed Central and Obstructive Sleep Apnea" OR "Sleep Apnea, Mixed" OR "Mixed Sleep Apnea" OR "Mixed Sleep Apneas" OR "Sleep Apneas, Mixed" OR "Hypersomnia with Periodic Respiration")).

The same strategy was used in the case of the Cochrane Library, since it also employs MeSH terms.

The Embase database was searched using the Emtree preferred terms and supplementary data: "Orthognathic surgery" /exp AND "Obstructive Sleep Apnea"/syn.

Grey literature from the Google Scholar Beta database was also searched in order to retrieve studies published in journals not indexed in the major databases. All duplicates from the four systematic searches were subsequently removed.

\section{Study selection}

The electronic search was conducted by two authors (MG-H and AV-O) to avoid subjectivity. Those studies that fulfilled the inclusion criteria were retrieved for fulltext reading.

The inclusion criteria were intervention studies; patients $>18$ years of age with moderate to severe OSA (AHI $\geq 15$ events/hour) eligible for MMA; studies assessing the effect of orthognathic surgery on PA dimensions; studies assessing the impact of orthognathic surgery on PSG-related parameters; a minimum follow-up period of 6 months; and reporting of the magnitude of advancement of the maxilla, mandible and chin. Studies in which patients underwent turbinectomy and/or septoplasty as adjunctive procedures were also included, since these procedures do not modify PA dimensions. The exclusion criteria were case reports; literature reviews; and studies reporting patients undergoing setback orthognathic surgery or Hs, tonsillectomy, adenoidectomy or UPPP as adjunctive procedures, since these procedures may modify PA dimensions.

In the event of disagreement between the authors, the identified papers were subjected to full-text reading, and eligibility under discussion was then assessed. If any doubts arose, a third reviewer (FH-A) screened and read in full the included articles, and it was then discussed whether one of the authors had rejected it.

The level of inter-rater agreement between authors was assessed by Cohen's kappa coefficient $(\kappa)$.

\section{Data extraction}

Demographic, surgical and methodological data were compiled from the included studies. Any discrepancies were resolved by consensus between the authors (MG-H and $\mathrm{AV}-\mathrm{O})$.

\section{Outcome measures}

The following outcome measures were evaluated: AHI, PA dimensions, and SRs and CRs, respectively.
Regarding the AHI assessment, it was established as the final postoperative score (final AHI) and the presurgery versus postsurgery difference (AHI reduction). Moreover, final AHI was assessed to establish the 'SRs' and 'CRs' of surgical treatment of OSA after MMA, as described elsewhere. ${ }^{14-6}$ 17-25 $\mathrm{A}$ final AHI of $<20$ events/ hour, with a reduction of $50 \%$ postoperatively, defines surgical success. ${ }^{157} \mathrm{~A}$ final AHI of $<5$ events/hour is regarded as a surgical cure criterion. ${ }^{14-617-25}$

As to PA enlargement evaluation, both 3D and 2D measures assessed by CBCT and cephalometric analysis, respectively, were included as primary indicators of the anatomical changes as follows: PAV and pharyngeal airway space (PAS) gain (in $\mathrm{cm}^{3}$ and $\mathrm{mm}$, respectively).

Finally, as key independent variables, the magnitudes of maxillary and mandibular (in $\mathrm{mm}$ ) advancement, as well as the ratio between maxillary and mandibular advancement, were extracted from the included studies.

\section{Statistical analysis}

The statistical analysis included a demographic study (mean, SD, range and median for continuous variables, and absolute and relative frequencies for categorical variables). Paired t-tests were used to compare preoperative and postoperative mean values. Statistically significant differences were considered for $\mathrm{p}<0.05$. The R V.3.0.2 statistical package was used throughout.

\section{Study of heterogeneity and risk of bias}

The Preferred Reporting Items for Systematic Reviews and Meta-Analyses ${ }^{26}$ statements were used as a basis to ensure transparency of the systematic review, comprising 27 checklist items (referred to title, abstract, introduction, methods, results, discussion and funding) and a fourphase flowchart (identification, screening, eligibility and inclusion) ${ }^{26}{ }^{27}$ Heterogeneity among the included items was assessed using the $\mathrm{I}^{2}$ statistics and a corresponding statistical null test. Galbraith plots were used to visualise the degree of heterogeneity. In situations of significant heterogeneity, the source was explored through sensitivity analysis.

Subgroup analyses were made to examine the different surgical techniques of the studies since genioplasty (Gp), the surgical correction of the projection of the chin, can add an increase in the PA. Thus, two surgical factors were considered for the two group analyses: (1) 'MMA group' ( $\mathrm{n}=108$ ), which excluded studies with Gp, ${ }^{17} 202224$ and (2) 'MMA \pm Gp' group $(\mathrm{n}=159)$, including all articles regardless of Gp. ${ }^{17-24}$ Forests plots were used to show the effects. A metaregression model was developed to assess the association between the largest number of studies regarding maxillary and/or mandibular advancement. These random effects were supported by the inverse variance method of DerSimonian and Laird. ${ }^{28}$ A $95 \%$ CI was pooled.

The quality of the papers was assessed using the adaptation of the bias analysis used by Haas et al. ${ }^{1629}$ The criteria 
Main search

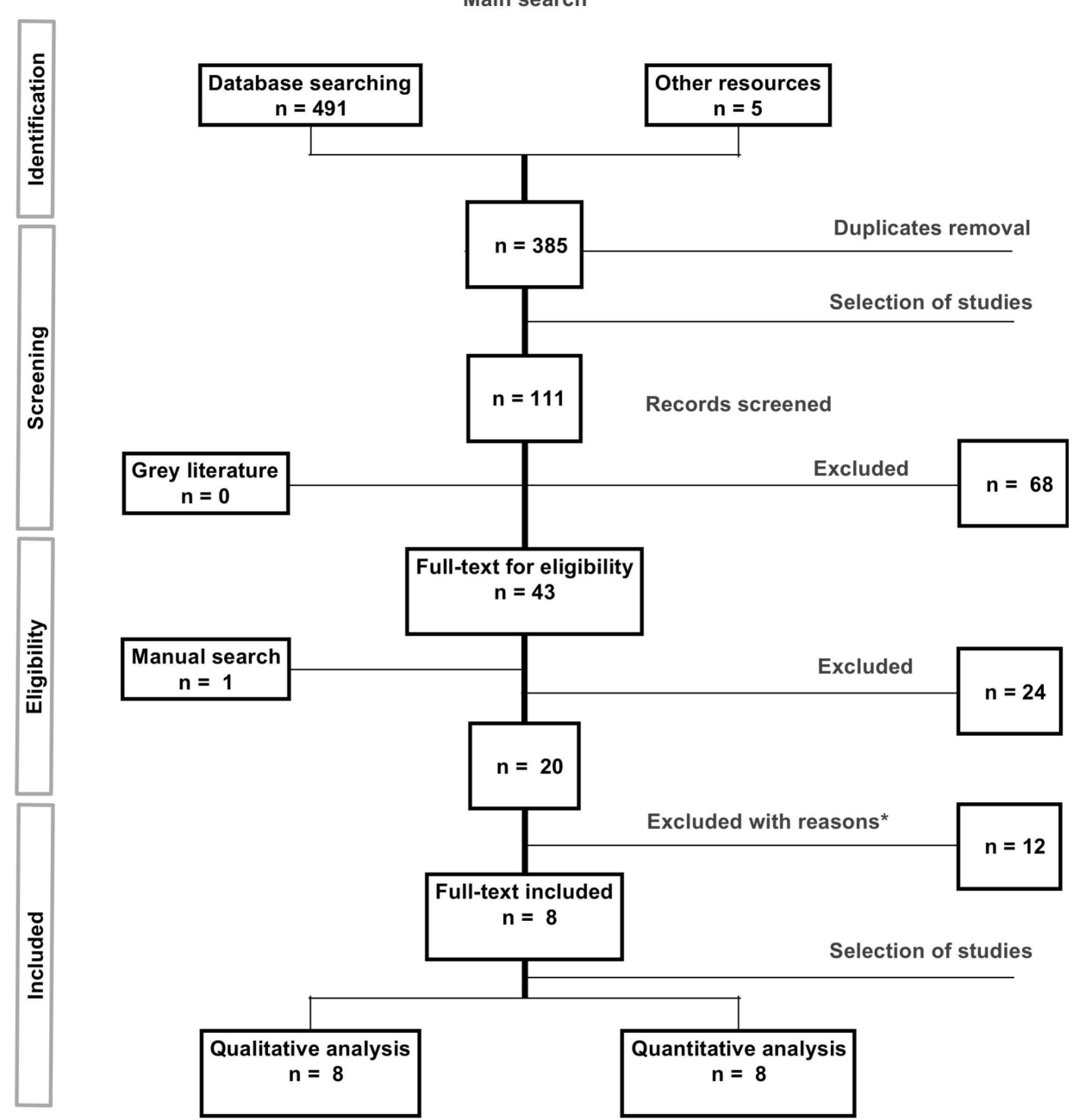

Figure 1 Systematic Preferred Reporting Items for Systematic Reviews and Meta-Analyses flowchart. *No response or inappropriate data were received from the authors of the excluded studies.

based on sample selection, blinding of the authors, comparison between treatments, statistical analysis and outcome validation measured the degree of bias, definition of inclusion and exclusion criteria, and postoperative follow-up. They were categorised as low risk if all the criteria were met, uncertain risk when only one criterion was missing, and high risk if two or more criteria were missing according to the analysis of Haas et al. ${ }^{16}$ With respect to publication bias, funnel plots and the Egger test were used.

\section{RESULTS}

\section{Search strategy and study selection}

The strategies of the main search and grey literature search were applied up to December 2017. A four-phase flowchart (identification, screening, eligibility and inclusion) is provided of each step of the systematic search, confirming the thoroughness of the screening process. The aim of this diagram was to help the authors improve the reporting of systematic reviews (figure 1)..$^{26}$

The main electronic search yielded a total of 496 articles. Of these, 491 were found in PubMed and 5 were found in the Cochrane Library and Embase databases. The titles and abstracts of 111 articles were scrutinised independently by the two investigators (MGH and AVO) after the removal of duplicates. Of these studies, 43 were subjected to full-text reading. The inter-rater agreement coefficient was $\kappa=0.856$ (95\% CI 0.773 to 1 ) for study selection.

\section{Study eligibility}

The same two authors independently evaluated the 43 articles subjected to full-text reading. Of these, 20 met the criteria for inclusion. The authors of four studies ${ }^{13} 30-32$ were contacted by email for further information, since some doubts arose during the selection process. A period of 4 weeks was allowed for their reply in providing the missing data, but no reply for further information was obtained from any of the authors. ${ }^{13} 30-32$

Twelve articles ${ }^{11} 13 \quad 30-39$ were excluded from the systematic review. Of the excluded studies, one ${ }^{35}$ failed to report the magnitude of movement during orthognathic surgery; eight studies ${ }^{11} 303133-37$ did not report PA 
measurements; and three studies ${ }^{36} 38$ reported setback procedures.

Eight studies ${ }^{17-24}$ were therefore included in the quantitative analysis. The inter-rater agreement regarding study eligibility was considered excellent, with $\kappa=0.813$ (95\% CI 0.663 to 1.0$)$.

\section{Data extraction}

Data from the included studies are shown in table 1.

The included studies were mainly retrospective, ${ }^{17-21} 24$ and only two involved a prospective design. ${ }^{22} 23$ The meta-analysis sample consisted of a total of 159 patients from the eight included studies. Of these, four articles assessed the efficacy of MMA alone $(\mathrm{n}=108),{ }^{172022} 24$ while four trials ${ }^{18} 192123$ evaluated the effectiveness of MMA+Gp as an adjunctive procedure, though not necessarily in all the patients $(n=51){ }^{18} 192123$ Since Gp may add an increase in PA, subgroup analyses were made to examine the different surgical techniques used in the studies: (1) MMA group $(\mathrm{n}=108)$, which excludes studies with Gp, ${ }^{17} 2022$ and (2) MMA \pm Gp group $(n=159)$, which includes all articles regardless of $\mathrm{Gp}^{17-24}$ (tables 1 and 2).

No gender differences were identified in any study, though the male sample was larger in all the included studies (total of 116 men and 28 women).${ }^{17-24}$ The mean age was 39 years (range 33-61). ${ }^{17-24}$

All of the studies ${ }^{17-24}$ included patients with moderate to severe OSA assessed by PSG. In relation to the PSG parameters, most of the studies used the AHI. ${ }^{17} 1924$ However, one publication ${ }^{18}$ used the respiratory disturbance index (consisting of the apnoeas+hypopnoeas and arousals). Both metrics were considered equivalent when assessing OSA severity. ${ }^{5}$ In particular, the patients eligible for MMA included in this systematic review were not able to adhere to CPAP therapy (defined as $>4$ hours of night use of CPAP during $70 \%$ of nights) ${ }^{6}$ or failed previous adjunctive surgery, such as UPPP, Hs or adenoidectomy, among others. ${ }^{17-24}$

Regarding the imaging techniques used, the majority of the studies ${ }^{17}{ }^{20-23}$ assessed the PA measurements with 3D methods (CBCT). In all studies, patients were scanned sitting in an upright position in the Frankfort horizontal plane. This position is closer to the natural head position and is recommended for the baseline assessment of upper airway dimensions. ${ }^{8-14}$ Of these publications, five reported 3D PA measurements (PAV), ${ }^{1720-23}$ and three reported 2D PA measurements ${ }^{18} 194$ in the sagittal plane (PAS), consisting of the minimum distance between the base of the tongue and the posterior pharyngeal wall 1824 (table 3).

\section{Quantitative analysis}

The meta-analysis estimated the effects of the PSG parameters (final AHI, AHI reduction, SR and CR) and PA measurements (3D PAV gain or 2D PAS gain) in relation to the maxillary and mandibular advancement achieved in the eight studies regardless of Gp (MMA \pm Gp group). ${ }^{17-24}$ In a second stage, the analyses were replicated for the studies reporting only MMA (MMA group) ${ }^{17202224}$ in order to evaluate the sole effect of the MMA, without Gp. Metaregression was estimated at the time of assessment of the effects in terms of the magnitude of maxillary and mandibular advancement and the maxillary:mandibular ratio related to $\mathrm{AHI}$ as independent variables. ${ }^{40}$

\section{Effect of MMA on AHI}

Data on the outcomes assessed in this meta-analysis can be extracted from tables 2 and 3 .

Regarding the final $A H I$ in both groups: (1) $\mathrm{MMA} \pm \mathrm{Gp}$ group $^{17-24}$ : the mean postoperative AHI scores for the global sample of 159 patients ranged from $4.8^{22}$ to 29.4 events $/$ hour ${ }^{18}$ with a mean final AHI of 12.4 events/hour (95\% CI 7.18 to $17.6, \mathrm{p}<0.001$ ) (figure $2 \mathrm{~A})$. The results suggest that the treatment ensures a final AHI value below the threshold of 20 on average. Specifically, the $p$ values for metaregression of the maxillary, mandibular and maxillary:mandibular ratio were $0.073,0.747$ and 0.316, respectively. A strong tendency was seen, though no significant effects were detected for any of them separately. (2) MMA group ${ }^{17} 2022$ 24: a global sample of 108 patients who did not undergo Gp yielded a mean postoperative AHI score of $4.8^{22}$ to $18.6^{17}$ events/hour. The mean final AHI score was 12.9 events/hour (95\% CI 6.94 to $18.85, \mathrm{p}<0.001$ ), which suggests that the treatment ensures a final AHI value below the threshold of $20 .{ }^{17} 202224$ Individually, no significant effect was shown for maxillary advancement $(\mathrm{p}=0.200)$, though a statistically significant effect was detected for both mandibular advancement and the maxillary:mandibular ratio ( $\mathrm{p}=0.025$ and 0.002 , respectively). For every additional $1 \mathrm{~mm}$ of mandibular advancement, the final AHI score was reduced by an average of 1.45 events/hour, ${ }^{17} 202224$ and for every additional unit of maxillary:mandibular ratio, the final AHI score was reduced by an average of 0.81 events/hour, ${ }^{17} 202224$ respectively.

On the other hand, results regarding AHI reduction were as follows: (1) $\mathrm{MMA} \pm \mathrm{Gp}$ group ${ }^{17-24}$ : the average reduction values ranged between $30.9^{17}$ and 50.6 events/ hour. ${ }^{19}$ The mean estimated overall effect for AHI reduction was 38.0 events/hour (95\% CI 31.7 to 44.3$)(\mathrm{p}<0.001)$ (figure 2B). Metaregression analysis referred to the magnitude of maxillary and mandibular advancement, and the maxillary:mandibular ratio yielded no statistically significant results for any of the groups $(\mathrm{p}=0.977$, 0.263 and 0.520 , respectively). (2) MMA group ${ }^{17} 2022$ : the average reduction values ranged between $30.9^{22}$ and 50.6 events $/$ hour ${ }^{17}$ for the sample of 108 patients. A statistically significant mean decrease in AHI of 39.0 events/ hour $(95 \%$ CI 31.5 to $46.6, \mathrm{p}<0.001)$ was obtained. In particular, the maxillary advancement had a significant effect on the reduction of AHI $(p=0.044)$. Hence, for each additional $1 \mathrm{~mm}$ of maxillary advancement, the AHI further decreased by 1.34 events/hour. However, no 


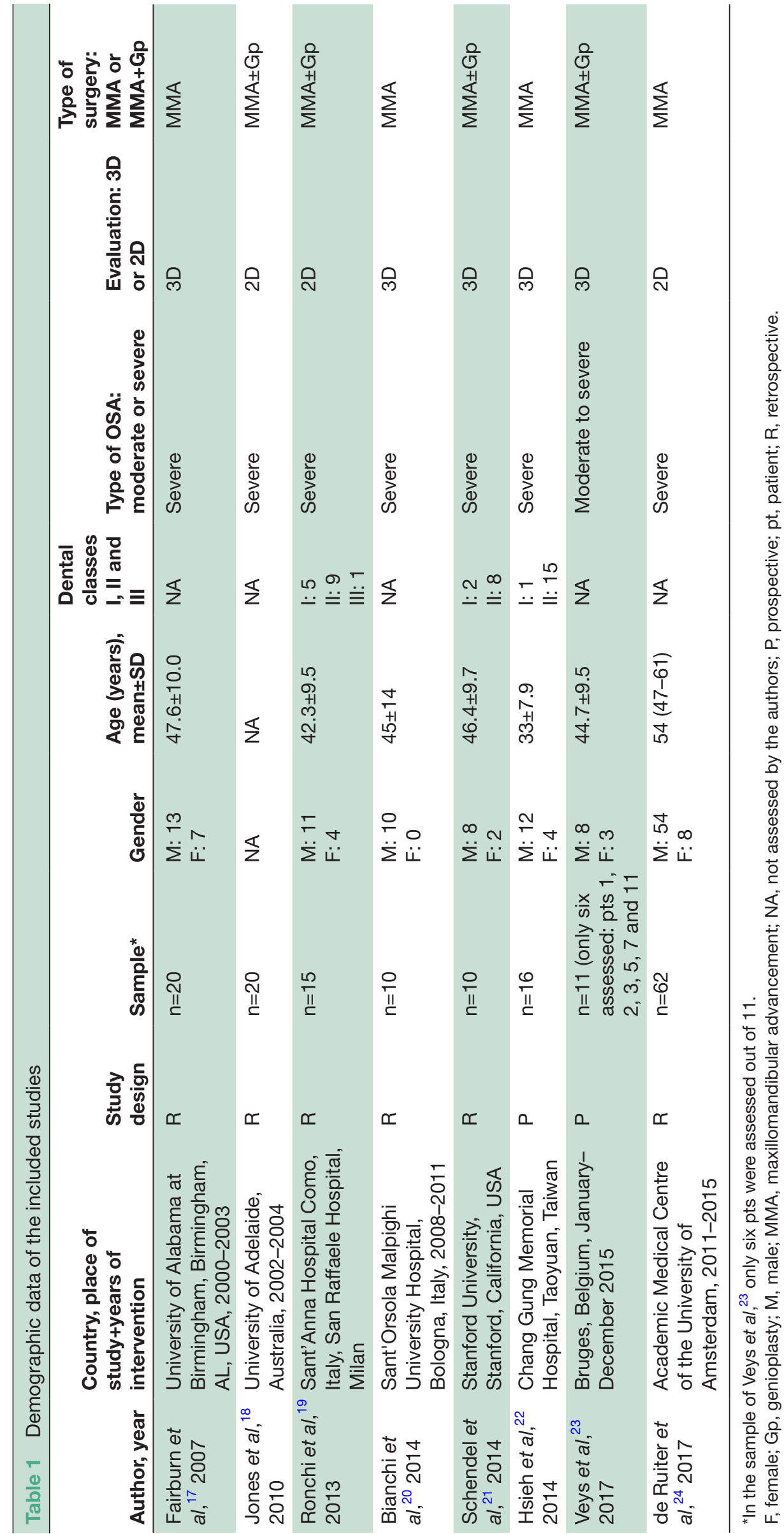


Table 2 Data referred to outcome measures of the included studies

\begin{tabular}{|c|c|c|c|c|c|c|c|c|}
\hline Author, year & Sample* & $\begin{array}{l}\text { Pre-BMI } \\
\left(\mathrm{kg} / \mathrm{m}^{2}\right)\end{array}$ & $\begin{array}{l}\text { Post-BMI } \\
\left(\mathrm{kg} / \mathrm{m}^{2}\right)\end{array}$ & $\begin{array}{l}\text { Type of } \\
\text { surgery: } \\
\text { MMA or } \\
\text { MMA } \pm \text { Gp }\end{array}$ & $\begin{array}{l}\text { Pre-AHI } \\
\text { mean } \pm \text { SD } \\
\text { (events/hour) }\end{array}$ & $\begin{array}{l}\text { Post-AHI } \\
\text { mean } \pm \text { SD } \\
\text { (events/hour) }\end{array}$ & $\begin{array}{l}\text { Success } \\
\text { rate }\end{array}$ & $\begin{array}{l}\text { Cure } \\
\text { rate }\end{array}$ \\
\hline $\begin{array}{l}\text { Fairburn et } \\
\text { al, }{ }^{17} 2007\end{array}$ & $n=20$ & $32.24 \pm 4.7$ & $\begin{array}{l}31.74 \pm 5.0 \\
(p=0.61)\end{array}$ & MMA & $69.2 \pm 35.8$ & $18.6 \pm 6.3$ & $90 \%$ & $50 \%$ \\
\hline $\begin{array}{l}\text { Jones et al, }{ }^{18} \\
2010\end{array}$ & $n=20$ & $\begin{array}{l}33.9 \pm 8.5 \\
(p=0.61)\end{array}$ & $\begin{array}{l}34.7 \pm 9.2 \\
(p=0.61)\end{array}$ & $M M A \pm G p$ & $\begin{array}{l}61.41 \pm 19.6 \\
(p>0.01)\end{array}$ & $\begin{array}{l}29.4 \pm 19.4 \\
(p>0.01)\end{array}$ & $65 \%$ & NA \\
\hline $\begin{array}{l}\text { Ronchi et } \\
\text { al }{ }^{19} 2013\end{array}$ & $n=15$ & NA & NA & $M M A \pm G p$ & $\begin{array}{l}58.7 \pm 16 \\
(p<0.001)\end{array}$ & $\begin{array}{l}8.1 \pm 7.8 \\
(p<0.001)\end{array}$ & $100 \%$ & NA \\
\hline $\begin{array}{l}\text { Bianchi et } \\
a l,{ }^{20} 2014\end{array}$ & $n=10$ & NA & NA & MMA & $\begin{array}{l}56.8 \pm 16.6 \\
(p<0.005)\end{array}$ & $\begin{array}{l}12.3 \pm 5.5 \\
(p<0.005)\end{array}$ & $100 \%$ & NA \\
\hline $\begin{array}{l}\text { Schendel et } \\
\text { al, }{ }^{21} 2014\end{array}$ & $n=10$ & 28.6 & NA & $M M A \pm G p$ & $42.9 \pm 21.2$ & $5.2 \pm 8.3$ & $100 \%$ & NA \\
\hline $\begin{array}{l}\text { Hsieh et al, }{ }^{22} \\
2014\end{array}$ & $\mathrm{n}=16$ & $22 \pm 3.3$ & NA & MMA & $\begin{array}{l}35.7 \pm 18.0 \\
(p<0.001)\end{array}$ & $\begin{array}{l}4.8 \pm 4.4 \\
(p<0.001)\end{array}$ & $100 \%$ & NA \\
\hline $\begin{array}{l}\text { Veys et al, }{ }^{23} \\
2017^{*}\end{array}$ & $\mathrm{n}=11$ & NA & NA & $M M A \pm G p$ & $\begin{array}{l}27.7 \pm 14.7 \\
(p=0.005)\end{array}$ & $8.5 \pm 10(p=0.005)$ & $70 \%$ & $40 \%$ \\
\hline $\begin{array}{l}\text { de Ruiter et } \\
\text { al, }{ }^{24} 2017\end{array}$ & $n=62$ & $\begin{array}{l}29(27-33) \\
(p=0.609)\end{array}$ & NA & MMA & $52 \pm 10(p=0.515)$ & $16 \pm 10(p=0.515)$ & $71 \%$ & NA \\
\hline
\end{tabular}

${ }^{*}$ In the sample of Veys et al, ${ }^{23}$ only six pts were assessed out of 11 (pts 1, 2, 3, 5, 7 and 11).

$\dagger P$ values $<0.05$ were considered as significant $(95 \% \mathrm{Cl})$.

AHI, apnoea-hypopnoea index; BMI, body mass index; Gp, genioplasty; MMA, maxillomandibular advancement;NA, not assessed by the authors; pt, patient.

significant effect was shown for mandibular advancement $(\mathrm{p}=0.544)$ or maxillary:mandibular ratio $(\mathrm{p}=0.258)$.

Finally, in relation to SR, both groups achieved high surgical SRs. An overall SR of $87.5 \%$ (95\% CI $76.8 \%$ to $98.2 \%$ ) and $90.3 \%$ (95\% CI $>76.8 \%$ ) was obtained for the $\mathrm{MMA} \pm \mathrm{Gp}$ and MMA groups, respectively (figure 3 ). However, no statistically significant associations were found between maxillary, mandibular advancement and maxillary:mandibular ratio $(\mathrm{p}=0.289, \mathrm{p}=0.901$ and $\mathrm{p}=0.394$, respectively) in any group.

\section{Effect of MMA on PAS and PAV}

With regard to the $2 D P A S$ increase, the following results were found in each group: (1) MMA \pm Gp group ${ }^{17-19} 2124$ : five studies comprising a sample of 127 patients reported 2D PA measurements. The overall mean PAS gain was $4.75 \mathrm{~mm}$ (95\% CI 3.15 to 6.35 ) and proved to be statistically significant $(\mathrm{p}<0.001)$ (figure 4$)$. Metaregression analysis yielded no statistically significant results for maxillary advancement or the maxillary:mandibular ratio $(\mathrm{p}=0.211$ and 0.560 , respectively). However, mandibular advancement was found to be statistically significant in terms of PAS gain $(\mathrm{p}<0.001)$. Our results suggest that the greater the mandibular advancement, the greater the PAS gain: each additional $1 \mathrm{~mm}$ of mandibular advancement implied a $0.5 \mathrm{~mm}$ gain in PAS.

(2) MMA group: only two studies ${ }^{1724}$ comprising a total of 82 patients reported 2D PA measurements with a mean PAS gain of $6.48 \mathrm{~mm}$ (95\% CI 5.31 to $7.64, \mathrm{p}<0.001)$.
Since only two papers are included in this group, a reliable metaregression analysis was not possible.

On the other hand, only two studies, ${ }^{20}{ }^{22}$ included within both groups (MMA $\pm \mathrm{Gp}$ and MMA), reported data on absolute 3D PAV gain. The mean PAV gain was $7.35 \mathrm{~cm}^{3}$ (95\% CI 5.35 to 9.34 ) and proved to be statistically significant $(p<0.001)$. Since only two papers are included in this group, a reliable metaregression analysis was not possible.

\section{Correlation between PAS/PAV gain and AHI}

Regarding 2D PA measurements, only four studies corresponding to the $\mathrm{MMA} \pm \mathrm{Gp}$ group (comprising a sample of 107 patients) reported information on PAS gain and final AHI/AHI reduction. ${ }^{17} 192124$ A statistically significant association was found between PAS gain and final AHI $(r=0.41, p=0.023)$, meaning that for each $1 \mathrm{~mm}$ of PAS gain, AHI was reduced in 3.58 events/hour $(95 \%$ CI 0.49 to 6.68$)$. Therefore, a greater change in PAS would result in a lower final AHI ${ }^{17} 192124$ (online supplementary figure S1).

With regard to the $3 D P A$ measurements, two papers, ${ }^{20}{ }^{22}$ included within both groups $(\mathrm{MMA} \pm \mathrm{Gp}$ and MMA), provided correlations between PAV and AHI reduction in a sample of 72 patients. Both studies obtained positive correlations (Pearson correlation coefficient (r) 0.576 according to Bianchi ${ }^{20}$ and 0.76 according to de Ruiter et al. ${ }^{24}$ The global effect estimated for the correlation was 0.75 (95\% CI 0.65 to 0.85$)$, reflecting a 


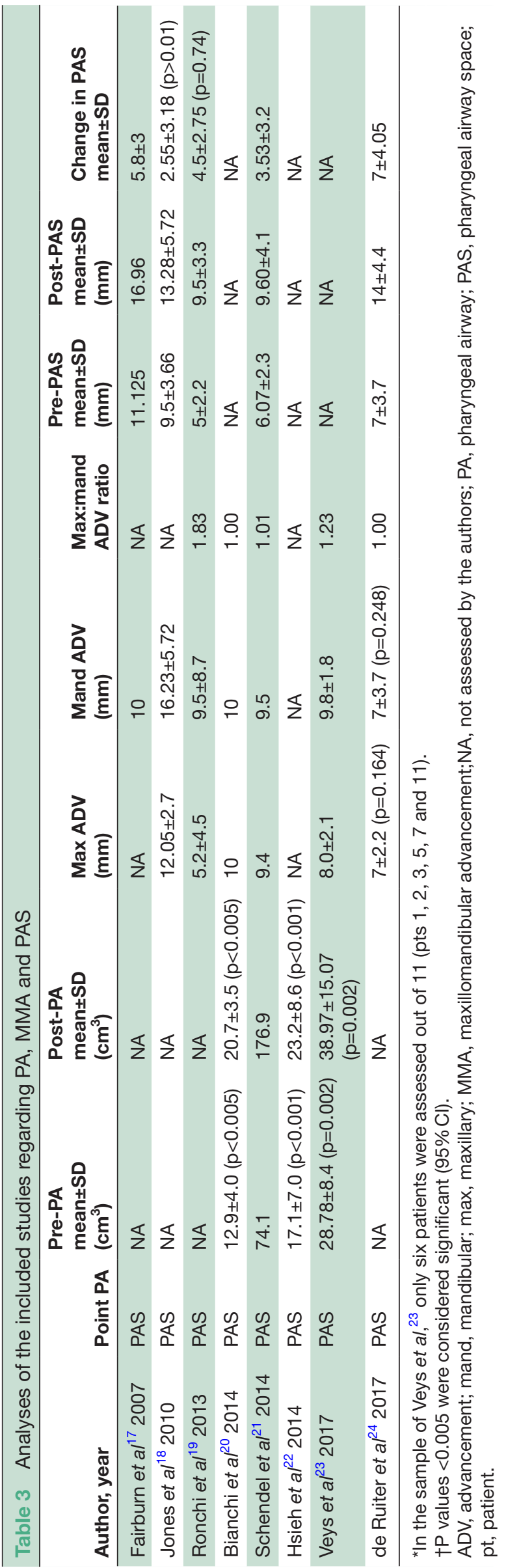

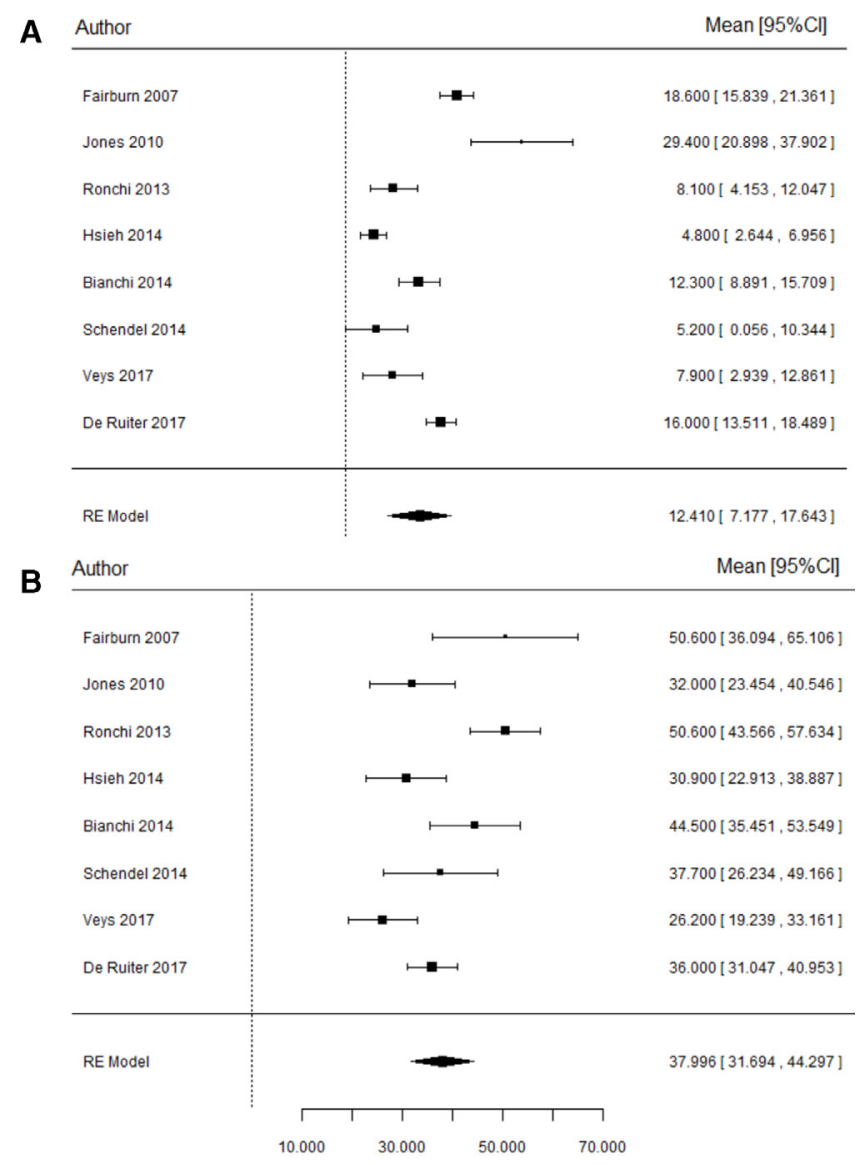

Figure 2 Forest plots representing the final mean $\mathrm{AHI}$ (A) and $\mathrm{AHI}$ reduction $(\mathrm{B})$ for both groups. $\mathrm{AHI}$, apnoeahypopnoea index.

strong relationship between changes in both variables. Therefore, the greater the volume gain, the greater the corresponding AHI reduction.

\section{Analysis of publication bias}

Data reporting the risk of bias are shown in table 4 . The risk of bias of the papers included in this systematic review was classified as high for five studies ${ }^{17-19} 2124$ and as medium/unclear for three studies. ${ }^{2022}{ }^{23}$ None of the studies reported blind assessment.

Funnel plots were used to depict the risk of publication bias. No publication bias was detected for final AHI (Egger test $\mathrm{p}=0.547$ for MMA and $\mathrm{p}=0.297$ for $\mathrm{MMA} \pm \mathrm{Gp}$ ) or PAS gain (Egger test $\mathrm{p}=0.156$ for MMA and $\mathrm{p}=0.109$ for $M M A \pm G p)$. Sensitivity analysis of the estimates identified two publications ${ }^{1718}$ as potentially being responsible for most of the heterogeneity between studies. Disparity between data was due to the patient sample regarding OSA severity. In terms of final AHI, heterogeneity accounted for $94.6 \%$ of the total variability, with $Q=102.9$ $(\mathrm{p}<0.001)$. The problem seemed to point primarily to one study, ${ }^{18}$ with a fairly high value in comparison with the other studies. No publication bias was likewise suggested with respect to PAS gain. 


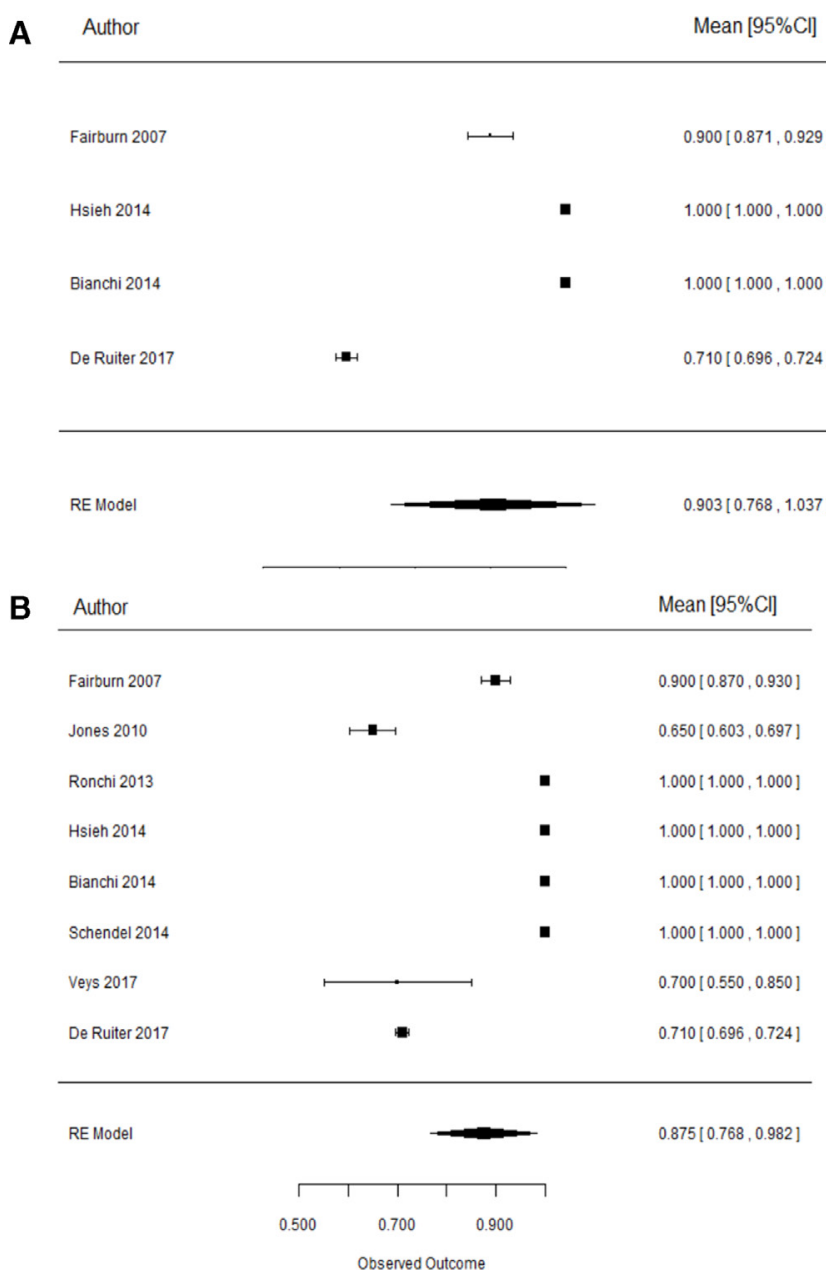

Figure 3 Forest plots corresponding to the success rate for both groups, (A) 'MMA' and (B) MMA \pm genioplasty'. MMA, maxillomandibular advancement.

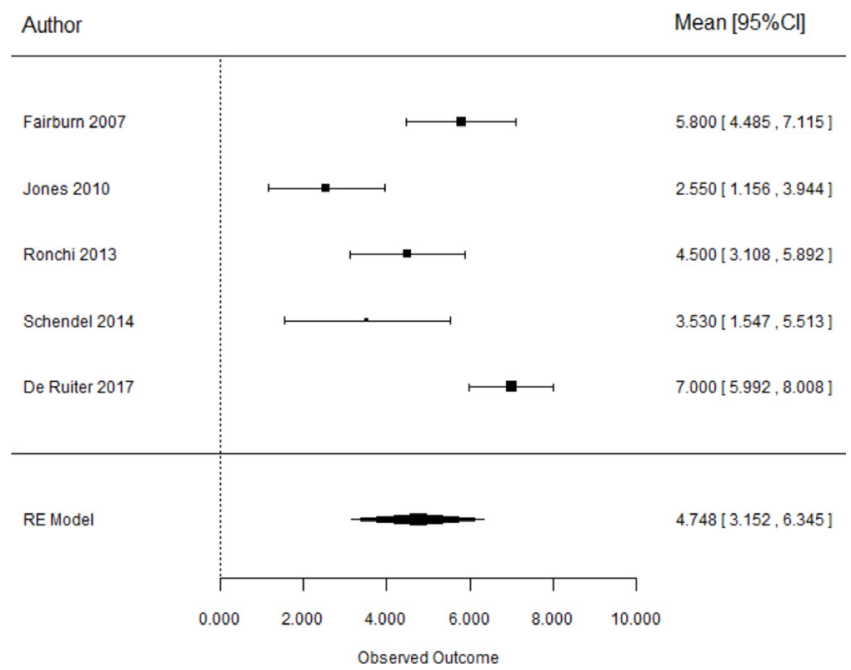

Figure 4 Forest plots representing pharyngeal airway space gain for both the 'MMA' and 'MMA \pm genioplasty' groups. MMA, maxillomandibular advancement.

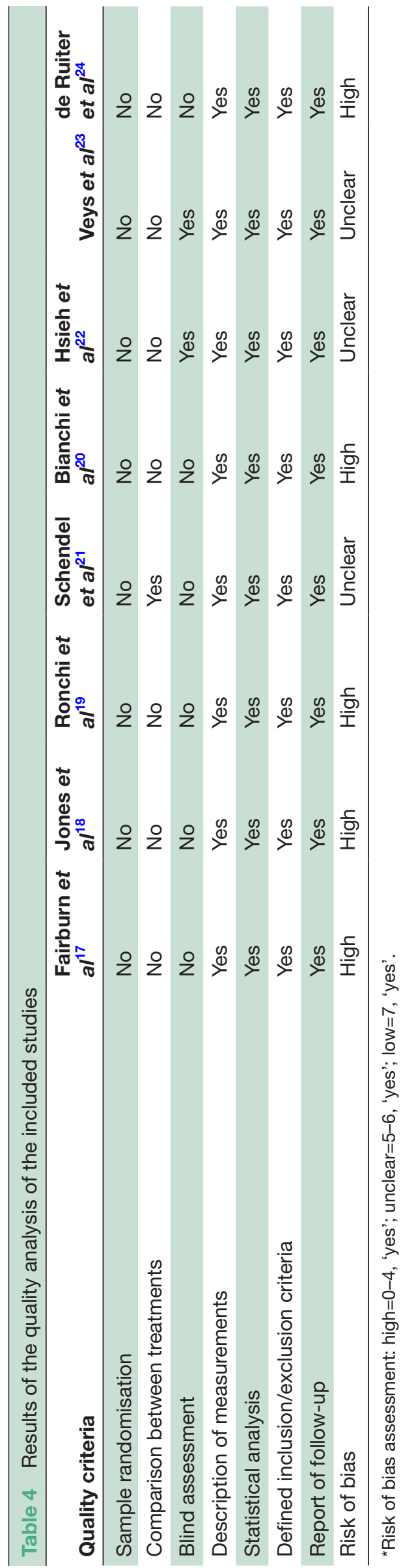


However, regarding AHI reduction, sensitivity analysis suggested that all the aforementioned heterogeneity could be due to maxillary advancement in the MMA group, given the adjustment found $\left(\mathrm{I}^{2}=0.0 \%, \mathrm{Q}=0.85\right.$, $\mathrm{p}=0.357$ ). This could be due to studies ${ }^{17}$ that reported large reductions in AHI. The Egger test yielded a low $p$ value $(\mathrm{p}=0.144)$, taking into account its limited power in application to these sample sizes. In contrast, homogeneity between studies was found on assessing PA $\left(\mathrm{I}^{2}=0 \%\right.$, $\mathrm{Q}=0.64, \mathrm{p}=0.422$ ).

\section{DISCUSSION}

The aim of the present systematic review with metaregression analysis was to assess the impact of MMA on $\mathrm{PA}$ dimensions and AHI in the treatment of OSA, as there is limited evidence regarding their exact correlations. ${ }^{17-24}$ Indeed, it has been widely reported that MMA increases PA and decreases AHI in the context of OSA, but additional multidisciplinary studies assessing aspects other than PA and AHI are needed to determine which types of maxillary, mandibular and chin movements (eg, advancement, rotation, impaction and descent) are best for enlarging the PA in its specific compromised levels and for finally reducing AHI, as well as patient characterisation in terms of OSA severity, comorbidities and facial profile, among other factors. ${ }^{51-43}$

With regard to MMA surgery according to the analysed articles, ${ }^{17-24}$ the positive effect of the intervention was clearly evidenced by the surgical SR obtained $(87.5 \%)$. However, while most of the included studies ${ }^{19} 2022$ obtained SR values of $100 \%$, Jones $e t$ al $^{18}$ recorded the lowest rate $(65 \%)$. Specifically, a mean final AHI of 12.4 events/hour (95\% CI 7.18 to $17.6, \mathrm{p}<0.01)^{17-24}$ was achieved in all of the literature reviewed. Hence, orthognathic surgery in application to OSA ensures surgical success with a final AHI of $<20$ events/hour and an AHI reduction of at least $50 \%$ according to the criteria defined by Riley et $a l^{34}$ However, some patients would still require ongoing CPAP treatment after MMA, since OSA may not be cured (AHI $<5$ events/hour), ${ }^{534}$ and would eventually have more difficulty in adhering to CPAP after surgery. ${ }^{44}$ None of the included studies reported the number of patients requiring ongoing CPAP after MMA. ${ }^{17-24}$ However, the surgical success criterion remains subject to controversy. ${ }^{544}$ In this regard, some authors suggest that surgical success in OSA should be assessed on the basis of improvement or resolution of the clinical signs and symptoms of OSA, the normalisation of sleep, AHI reduction $(\mathrm{AHI}<20)$ and quality of life. ${ }^{44}$ On the other hand, surgical CRs (AHI $<5$ events/hour) were assessed by only two studies (Fairburn et $a l^{17}$ and Veys et al, ${ }^{23}$ with CRs of $50 \%$ and $40 \%$, respectively (table 2). ${ }^{1723}$ Thus, we were not able to draw definitive conclusions on the impact of MMA on CRs. ${ }^{17} 23$

Scarce data are available on the required MMA advancement to benefit patients with OSA. ${ }^{5}{ }^{4}$ In terms of the amount of surgical movement achieved, to date, an MMA of $10 \mathrm{~mm}$ has been considered the gold standard orthognathic surgery treatment in patients with OSA. ${ }^{34}$ Nevertheless, the combination of MMA with counterclockwise rotation has proven to be the movement with the strongest impact on PA. ${ }^{1781317-243441-43}$ However, there is not enough evidence to establish the magnitude and direction of maxillary or mandibular movement required in order to cure OSA. ${ }^{5}$ Our results in this meta-analysis showed that for each additional $1 \mathrm{~mm}$ of mandibular advance, the final AHI is reduced by 1.45 events/hour on average, ${ }^{1722}$ but further in-depth investigations would be helpful to carry out patient-tailored surgeries, depending on their skeletal facial profile, PA shape, OSA characteristics and patients' comorbidities. ${ }^{45} 46$

The surgical treatment of OSA through MMA is occasionally performed in combination with additional procedures such as septoplasty, turbinectomy, tonsillectomy, adenoidectomy, UPPP or genial tubercle advancement (GTA).$^{554142}$ As specified by the inclusion criteria, studies where patients underwent turbinectomy and/or septoplasty as adjunctive procedures were included since it is considered that these procedures do not modify PA dimensions. ${ }^{18} 192123 \mathrm{Hs}$, tonsillectomy, adenoidectomy or UPPP as adjunctive procedures were excluded since they may alter PA dimensions. ${ }^{18} 192123$ Regarding GTA and Gp, these procedures were included, provided that the magnitude of advancement was reported. ${ }^{18} 192123$ However, in order to discard any independent effect or impact of Gp in MMA in terms of AHI reduction, variation in PAS and PAV gains of the two group analyses assessing MMA alone and MMA with Gp were carried out. ${ }^{17-24}$

In the past decades, the effectiveness of MMA in modifying PAS and PA has been evaluated using 2D or 3D methods, respectively. ${ }^{14}$ All of the studies ${ }^{17-24}$ assessed PAV by means of CBCT or cephalometry, both techniques (2D and 3D) being considered a safe and predictable way to measure PA, though the former lacks the option of evaluating the transverse dimension. ${ }^{17-24}$ The PA was assessed two dimensionally in three of the included studies, ${ }^{18} 1924$ taking the minimum distance between the base of the tongue and the posterior pharyngeal wall, though not all of them indicated the exact landmarks/ reference points used. ${ }^{181924}$ A significant difference of $4.75 \mathrm{~mm}$ (95\% CI 3.15 to 6.35 ) between preoperative PAS and postoperative PAS was found. Particularly, mandibular advancement was seen to be statistically significant when considering PAS gain $(p<0.001)$ : $1 \mathrm{~mm}$ of mandibular advancement implied $0.5 \mathrm{~mm}$ gain in PAS. ${ }^{17-19} 2124$ However, only Hsieh et $a l^{22}$ and Veys et $a l^{23}$ reported 3D airway measurements, and these were evaluated at three different levels with respect to the limits of the PA subregions: nasopharynx, oropharynx and hypopharynx. ${ }^{14}$ Taking into account that orthognathic surgery impacts three dimensionally and in different subregions of the $\mathrm{PA},{ }^{14}$ further studies reporting volumetric data with different PA levels of measurement are needed, in addition to those included in our review ${ }^{17} 22234143$ Thus, it is important to standardise the PA measurements for 
homogeneity purposes and thus be able to draw relevant conclusions. ${ }^{145}$

Regarding the correlations between changes in PAS/ PAV and AHI reduction in terms of MMA, a statistically significant association between PAS gain and final AHI was found in four of the studies included in the meta-analysis $(p=0.023) .{ }^{171921}{ }^{24}$ For each $1 \mathrm{~mm}$ PAS gain, AHI was reduced by 3.58 events/hour. ${ }^{17} 192124$ With regard to the 3D studies, PAV gain and AHI reduction were positively correlated ( $\mathrm{r}=0.75,95 \%$ CI 0.65 to 0.85$),{ }^{20}{ }^{24}$ reflecting a strong relationship between changes in both dimensions. Thus, the greater the volume gain, the greater the AHI reduction.

OSA severity and its clinical signs and symptoms, as well as special patient features such as comorbidities and facial profile, among others, should be considered when dealing with patients with OSA. ${ }^{5}$ Regarding OSA severity, to date, MMA is indicated only in moderate to severe cases and not in mild OSA cases (AHI of $<5) .{ }^{5}$ All of the included articles established the type of OSA as moderate to severe in their inclusion criteria ${ }^{17-24}$ (table 1). However, it should be noted that two studies ${ }^{1722}$ reported AHI values at baseline that moved further away from the average (mean 57.9 events/hour, range $35.7 \pm 18.0^{17}$ to $69.2 \pm 35.8) .{ }^{22}$ Thus, further studies are needed in order to evaluate the impact of MMA in patients with mild OSA. Another relevant issue is the importance of a comprehensive assessment of the global OSA symptoms of the patient for diagnostic and disease monitoring purposes. ${ }^{4}$ EDS and quality of life can be subjectively evaluated through the use of multiple clinical tools and questionnaires, such as the Epworth Sleepiness Scale (ESS) and the OSA Functional Outcomes of Sleep Questionnaire, respectively. ${ }^{3523}$ Improvement of daytime sleepiness assessed by ESS was reported by one of the included studies. ${ }^{23}$ A significant decrease in EES from 14 (10-18) to 6 (4-7), preoperatively and postoperatively, was observed $(\mathrm{p}=0.0014){ }^{23}$

Moreover, anatomical factors such as body mass index (BMI) are relevant factors that compromise OSA. ${ }^{57}$ In our review, only two studies ${ }^{17} 18$ addressed preoperative and postoperative BMIs. In this context, a $10 \%$ of weight loss has been associated with a $26 \%$ decrease in final AHI. ${ }^{47}$ Nonetheless, untreated obesity is also considered a major risk factor for the progression of OSA. ${ }^{547}$ Another crucial factor is the patient's facial profile, since the maxillomandibular complex sustains the PA soft tissues. Facial analysis of many patients with OSA evidences maxillary or mandibular hypoplasia, which generally can be corrected by orthognathic surgery. ${ }^{48}$ Accordingly, mandibular advancement devices-apart from being an option for treating mild to moderate OSAare also useful in deciding which patients may benefit from surgical mandibular advancement in the context of OSA. Unfortunately, no similar maxillary devices for predicting the impact of maxillary advancement on OSA are available. ${ }^{5}$

The importance of non-anatomical factors in relation to sleep disturbance surgery outcomes has been underscored, including neuromuscular tone, rostral fluid shift, airway collapsibility and loop gain. ${ }^{46}{ }^{49} \mathrm{Li}$ et $a l^{49}$ attributed an average of $61 \%$ of the recorded variation in postoperative AHI to these parameters $(\mathrm{r}=0.47, \mathrm{p}<0.01){ }^{49}$ Therefore, anatomical and non-anatomical factors are of great value in the diagnosis and treatment of patients with OSA. ${ }^{45-47}$ Hence, the current literature suggests that a multidisciplinary strategy is strongly advisable, taking into account all the related factors in order to ensure the long-lasting success of surgical treatment. ${ }^{5549}$

Finally, our study has a number of significant limitations: (1) the main limitation is the fact that none of the included studies were randomised controlled clinical trials ${ }^{25}$; (2) few articles were included in the meta-analysis; (3) definitive generalisations cannot be made, given that of the eight studies included, ${ }^{17-24}$ only two were prospective; the remainder were retrospective and therefore subjected to the usual biases and limitations of retrospective studies ${ }^{40} ;(4)$ there was a lack of homogeneity among the studies regarding the PA measurements (2D or 3D); (5) some of the studies did not directly provide mean values or $\mathrm{SD}$, such data being calculated directly from the tables reporting individual patient values; (6) regarding the PSG parameters, most of the studies used the AHI ${ }^{17} 1924$; however, one publication ${ }^{18}$ used the respiratory disturbance index; and (7) no firm conclusions on the impact of MMA on surgical CR can be stated since only two studies reported CRs.

\section{CONCLUSIONS}

There is a lack of homogeneous and detailed data in the current literature regarding AHI reduction and PAS/PAV gain after MMA in patients with a retrusive facial profile. However, within the limitations of this systematic review, there is sufficient evidence to conclude that MMA significantly increases PA dimensions and ensures a final AHI score below the threshold of 20 events/hour, obtaining a mean SR of $87.5 \%$. However, further studies are needed to individualise the required magnitude and direction of surgery-induced movements for each patient.

\section{Author affiliations}

${ }^{1}$ Department of Oral and Maxillofacial Surgery, Universitat Internacional de Catalunya Facultat de Medicina i Ciencies de la Salut, Sant Cugat del Valles, Spain

${ }^{2}$ Department of Oral and Maxillofacial Surgery, Centro Medico Teknon, Barcelona, Spain

Acknowledgements The authors thank Juan Luís Gómez-Martínez for his help with the statistical analysis and Luís Álvarez-Reguera and Dorin Nevovici for their kind contribution to the entire study process.

Contributors All of the authors have seen and approved the manuscript and have given license for publication. All of the authors have contributed to planning, conduct and reporting of the work described in the article.

Funding The authors have not declared a specific grant for this research from any funding agency in the public, commercial or not-for-profit sectors.

Disclaimer All of the authors have seen and approved this manuscript and give license for publication.

Competing interests None declared. 
Patient consent for publication Not required.

Provenance and peer review Not commissioned; externally peer reviewed.

Data availability statement Data are available in a public, open access repository.

Open access This is an open access article distributed in accordance with the Creative Commons Attribution Non Commercial (CC BY-NC 4.0) license, which permits others to distribute, remix, adapt, build upon this work non-commercially, and license their derivative works on different terms, provided the original work is properly cited, appropriate credit is given, any changes made indicated, and the use is non-commercial. See: http://creativecommons.org/licenses/by-nc/4.0/.

\section{ORCID iD}

Maria Giralt-Hernando http://orcid.org/0000-0003-3329-4845

\section{REFERENCES}

1 Knudsen TB, Laulund AS, Ingerslev J, et al. Improved apnea-hypopnea index and lowest oxygen saturation after maxillomandibular advancement with or without counterclockwise rotation in patients with obstructive sleep apnea: a meta-analysis. $J$ Oral Maxillofac Surg 2015;73:719-26.

2 Lloberes P, Durán-Cantolla J, Martínez-García Miguel Ángel, et al. Diagnosis and treatment of sleep apnea-hypopnea syndrome. Spanish Society of pulmonology and thoracic surgery. Arch Bronconeumol 2011;47:143-56.

3 Durán J, Esnaola S, Rubio R, et al. Obstructive sleep ApneaHypopnea and related clinical features in a population-based sample of subjects aged 30 to 70 Yr. Am J Respir Crit Care Med 2001;163:685-9.

4 Kapur VK, Auckley DH, Chowdhuri S, et al. Clinical Practice Guideline for Diagnostic Testing for Adult Obstructive Sleep Apnea : An American Academy of Sleep Medicine Clinical Practice Guideline 2017; 13:479-504.

5 Dicus Brookes CC, Boyd SB. Controversies in obstructive sleep apnea surgery. Oral Maxillofac Surg Clin North Am 2017;29:503-13.

6 Weaver TE, Grunstein RR. Adherence to continuous positive airway pressure therapy: the challenge to effective treatment. Proc $\mathrm{Am}$ Thorac Soc 2008;5:173-8.

7 Guilleminault C, Tilkian A, Dement WC. The sleep apnea syndromes. Annu Rev Med 1976;27:465-84.

8 Holty J-EC, Guilleminault C. Maxillomandibular advancement for the treatment of obstructive sleep apnea: a systematic review and metaanalysis. Sleep Med Rev 2010;14:287-97.

9 Hernández-Alfaro F, Guijarro-Martínez R, Mareque-Bueno J. Effect of mono- and bimaxillary advancement on pharyngeal airway volume: cone-beam computed tomography evaluation. J Oral Maxillofac Surg 2011;69:e395-400.

10 Guijarro-Martínez R, Swennen GRJ. Cone-Beam computerized tomography imaging and analysis of the upper airway: a systematic review of the literature. Int J Oral Maxillofac Surg 2011;40:1227-37.

11 Prinsell JR. Obstructive sleep Apnea-Surgical treatment. in: current therapy in oral and maxillofacial surgery. Elsevier 2012:1048-63.

12 Prinsell JR. Maxillomandibular advancement surgery in a sitespecific treatment approach for obstructive sleep apnea in 50 consecutive patients. Chest 1999;116:1519-29.

13 Butterfield KJ, Marks PLG, McLean L, et al. Linear and volumetric airway changes after maxillomandibular advancement for obstructive sleep apnea. J Oral Maxillofac Surg 2015;73:1133-42.

14 Guijarro-Martínez R, Swennen GRJ. Three-Dimensional cone beam computed tomography definition of the anatomical subregions of the upper airway: a validation study. Int J Oral Maxillofac Surg 2013;42:1140-9.

15 Christovam IO, Lisboa CO, Ferreira DMTP, et al. Upper airway dimensions in patients undergoing orthognathic surgery: a systematic review and meta-analysis. Int J Oral Maxillofac Surg 2016;45:460-71.

16 Haas Jr. OL, Becker OE, de Oliveira RB. Computer-Aided planning in orthognathic surgery-systematic review. Int J Oral Maxillofac Surg 2015;44:329-42.

17 Fairburn SC, Waite PD, Vilos G, et al. Three-Dimensional changes in upper airways of patients with obstructive sleep apnea following maxillomandibular advancement. J Oral Maxillofac Surg 2007;65:6-12.

18 Jones R, Badlani J, Maxillary JC. Mandibular and chin advancement surgery for the treatment of obstructive sleep apnoea 2010;55:314-21.

19 Ronchi P, Cinquini V, Ambrosoli A, et al. Maxillomandibular advancement in obstructive sleep apnea syndrome patients: a restrospective study on the sagittal cephalometric variables. JOMR 2013;4:e5.

20 Bianchi A, Betti E, Tarsitano A, et al. Volumetric three-dimensional computed tomographic evaluation of the upper airway in patients with obstructive sleep apnoea syndrome treated by maxillomandibular advancement. Br J Oral Maxillofac Surg 2014;52:831-7.

21 Schendel SA, Broujerdi JA, Jacobson RL. Three-Dimensional upper-airway changes with maxillomandibular advancement for obstructive sleep apnea treatment. Am J Orthod Dentofacial Orthop 2014;146:385-93.

22 Hsieh Y-J, Liao Y-F, Chen N-H, et al. Changes in the calibre of the upper airway and the surrounding structures after maxillomandibular advancement for obstructive sleep apnoea. Br J Oral Maxillofac Surg 2014;52:445-51.

23 Veys B, Pottel L, Mollemans W, et al. Three-Dimensional volumetric changes in the upper airway after maxillomandibular advancement in obstructive sleep apnoea patients and the impact on quality of life. Int J Oral Maxillofac Surg 2017;46:1525-32.

24 de Ruiter MHT, Apperloo RC, Milstein DMJ, et al. Assessment of obstructive sleep apnoea treatment success or failure after maxillomandibular advancement. Int J Oral Maxillofac Surg 2017;46:1357-62.

25 Schulz KF, Altman DG, Moher D, et al. Consort 2010 statement: updated guidelines for reporting parallel group randomized trials. Ann Intern Med 2010;152:726.

26 Moher D, Liberati A, Tetzlaff J, et al. Preferred reporting items for systematic reviews and meta-analyses: the PRISMA statement. preferred reporting items for systematic reviews and meta-analyses. BMJ Br Med J 2010;8.

27 Liberati A, Altman DG, Tetzlaff J, et al. The PRISMA statement for reporting systematic reviews and meta-analyses of studies that evaluate health care interventions: explanation and elaboration. PLoS Med 2009;6:e1000100.

28 DerSimonian R, Laird N. Meta-Analysis in clinical trials. Control Clin Trials 1986;7:177-88.

29 Higgins JPT, Altman DG, Gøtzsche PC, et al. The Cochrane collaboration's tool for assessing risk of bias in randomised trials. BMJ 2011;343:d5928-9.

30 Susarla SM, Abramson ZR, Dodson TB, et al. Upper airway length decreases after maxillomandibular advancement in patients with obstructive sleep apnea. J Oral Maxillofac Surg 2011;69:2872-8.

31 Giarda M, Brucoli M, Arcuri F, et al. Efficacy and safety of maxillomandibular advancement in treatment of obstructive sleep apnoea syndrome. Acta Otorhinolaryngol Ital 2013;33:43-6.

32 Abramson Z, Susarla SM, Lawler M, et al. Three-Dimensional computed tomographic airway analysis of patients with obstructive sleep apnea treated by maxillomandibular advancement. J Oral Maxillofac Surg 2011;69:677-86.

33 Waite PD, Wooten V, Lachner J, et al. Maxillomandibular advancement surgery in 23 patients with obstructive sleep apnea syndrome. Journal of Oral and Maxillofacial Surgery 1989;47:1256-61.

34 Riley RW, Powell NB, Li KK, et al. Surgery and obstructive sleep apnea: long-term clinical outcomes. Otolaryngol Head Neck Surg 2000;122:415-20.

35 Abrahão M, Gregório LC, Gregório LC, et al. Genioplasty for genioglossus muscle advancement in patients with obstructive sleep apnea-hypopnea syndrome and mandibular retrognathia. Braz $J$ Otorhinolaryngol 2007;73:480-6.

36 Hasebe D, Kobayashi T, Hasegawa M, et al. Changes in oropharyngeal airway and respiratory function during sleep after orthognathic surgery in patients with mandibular prognathism. Int $J$ Oral Maxillofac Surg 2011;40:584-92.

37 Barrera JE. Virtual surgical planning improves surgical outcome measures in obstructive sleep apnea surgery. Laryngoscope 2014;124:1259-66.

38 Gokce SM, Gorgulu S, Gokce HS, et al. Evaluation of pharyngeal airway space changes after bimaxillary orthognathic surgery with a 3-dimensional simulation and modeling program. Am J Orthod Dentofacial Orthop 2014;146:477-92.

39 Uesugi T, Kobayashi T, Hasebe D, et al. Effects of orthognathic surgery on pharyngeal airway and respiratory function during sleep in patients with mandibular prognathism. Int J Oral Maxillofac Surg 2014;43:1082-90.

40 Thompson SG, Higgins JPT. How should meta-regression analyses be undertaken and interpreted? Stat Med 2002;21:1559-73.

41 Tan SK, Leung WK, Tang ATH, et al. How does mandibular advancement with or without maxillary procedures affect pharyngeal airways? an overview of systematic reviews. PLoS One 2017;12:e0181146-20. 
42 Bartolucci ML, Bortolotti F, Raffaelli E, et al. The effectiveness of different mandibular advancement amounts in OSA patients: a systematic review and meta-regression analysis. Sleep Breath 2016;20:911-9.

43 Sher AE, Schechtman KB, Piccirillo JF. The efficacy of surgical modifications of the upper airway in adults. Sleep 1976;19:156.

44 Hobson JC, Robinson S, Antic NA, et al. What is "Success" following surgery for obstructive sleep apnea? The effect of different polysomnographic scoring systems. Laryngoscope 2012;122:1878-81.

45 American Academy of Sleep Medicine. Time for surgeons to think outside the anatomical box. JCSM 2017;13:1023-4.
46 Sin DOND, Fitzgerald F, Parker JD, et al. Risk factors for central and obstructive sleep apnea in 450 men and women with congestive heart failure. Am J Respir Crit Care Med 1999;160:1101-6.

47 Romero-Corral A, Caples SM, Lopez-Jimenez F, et al. Interactions between obesity and obstructive sleep apnea: implications for treatment. Chest 2010;137:711-9.

48 Ristow O, Rückschloß T, Berger M, et al. Short- and long-term changes of the pharyngeal airway after surgical mandibular advancement in class II patients - a three-dimensional retrospective study. Journal of Cranio-Maxillofacial Surgery 2018;46:56-62.

$49 \mathrm{Li}$ Y, Ye J, Han D, et al. Physiology-Based modeling may predict surgical treatment outcome for obstructive sleep apnea. J Clin Sleep Med 2017;13:1029-37. 